\title{
Experimental investigation on an integrated thermal management system with heat pipe heat exchanger for electric vehicle
}

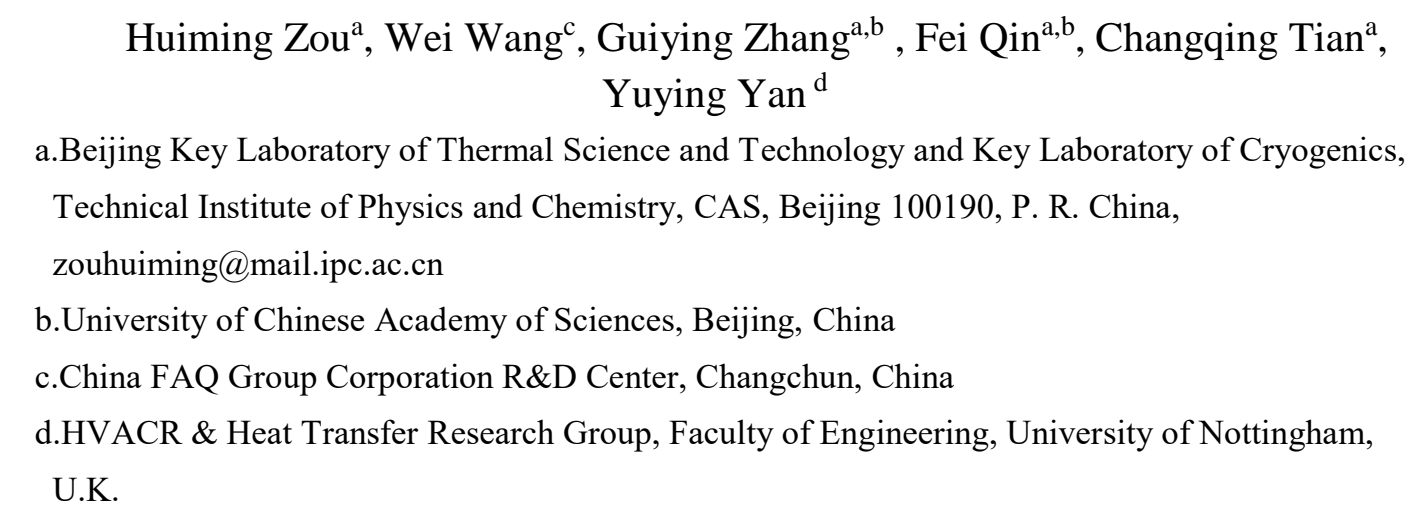

\section{Abstract:}

An integrated thermal management system combining a heat pipe battery cooling/preheating system with the heat pump air conditioning system is presented to fulfill the comprehensive energy utilization for electric vehicles. A test bench with battery heat pipe heat exchanger (HPHE) and heat pump air conditioning for a regular five-chair electric car is set up to research the performance of this integrated system under different working conditions. The investigation results show that as the system is designed to meet the basic cabinet cooling demand, the additional parallel branch of battery chiller is a good way to solve the battery group cooling problem, which can supply about $20 \%$ additional cooling capacity without input power increase. Its coefficient of performance( COP) for cabinet heating is around 1.34 at $-20^{\circ} \mathrm{C}$ out-car temperature and $20^{\circ} \mathrm{C}$ in-car temperature. The specific heat of the battery group is tested about $1.24 \mathrm{~kJ} / \mathrm{kg} \cdot{ }^{\circ} \mathrm{C}$. There exists a necessary temperature condition for the HPHE to start action. The heat pipe heat transfer performance is around $0.87 \mathrm{~W} /{ }^{\circ} \mathrm{C}$ 
27 on cooling mode and $1.11 \mathrm{~W} /{ }^{\circ} \mathrm{C}$ on preheating mode. The gravity role makes the heat

28 transfer performance of the heat pipe on preheating mode better than that on cooling

29 mode.

31 Key words: Electric vehicles, Heat pump, Heat pipe, Battery temperature control,

32 Thermal management

33 Nomenclature:

$34 A_{\mathrm{hp}} \quad$ contact superficial area with coolant of each heat pipe $\left(\mathrm{m}^{2}\right)$

$35 c_{\mathrm{b}} \quad$ specific heat of battery group $\left(\mathrm{kJ} / \mathrm{kg}^{\circ} \mathrm{C}\right)$

$36 c_{\mathrm{c}} \quad$ specific heat of coolant $\left(\mathrm{kJ} / \mathrm{kg}^{\circ} \mathrm{C}\right)$

$37 \quad m_{\mathrm{b}} \quad$ mass of battery group $(\mathrm{kg})$

$38 m_{\mathrm{c}} \quad$ mass of coolant $(\mathrm{kg})$

$39 n$ heat pipe number

$40 \quad Q_{\text {bi }} \quad$ batteries internal heat variation $(\mathrm{kW})$

$41 \quad Q_{\mathrm{c}} \quad$ cooling capacity by battery chiller $(\mathrm{kW})$

$42 Q_{\text {ci }} \quad$ coolant internal heat variation $(\mathrm{kW})$

$43 \quad Q_{\mathrm{g}} \quad$ generated heat by batteries $(\mathrm{kW})$

$44 \quad Q_{\mathrm{p}} \quad$ preheating heat by PTC $(\mathrm{kW})$

$45 \quad Q_{\mathrm{t}} \quad$ transferred heat by HPHE $(\mathrm{kW})$

$46 q_{\mathrm{hp}} \quad$ heat transfer coefficient of each heat pipe $\left(\mathrm{W} /{ }^{\circ} \mathrm{C}\right)$

$47 \quad T_{\text {ba }} \quad$ average temperature of battery group $\left({ }^{\circ} \mathrm{C}\right)$ 
$T_{b o} \quad$ coolant outlet temperature $\left({ }^{\circ} \mathrm{C}\right)$

$49 T_{b i} \quad$ coolant inlet temperature $\left({ }^{\circ} \mathrm{C}\right)$

$50 \quad T_{\text {ca }} \quad$ coolant average temperature $\left({ }^{\circ} \mathrm{C}\right)$

$51 \Delta T \quad$ average temperature difference between the battery group and the coolant $\left({ }^{\circ} \mathrm{C}\right)$

$52 t \quad$ time (s)

\section{Introduction}

Electric vehicle (EV) is an important development orientation to alleviate the traditional automobile exhaust problem. However, thermal management including battery temperature control and cabinet air conditioning is a big challenge for $\mathrm{EV}$, as the traditional engine and oil tank are replaced by electric motor and battery groups.

Lots of heat inside of the battery generated by the electrochemical reaction will raise the battery temperature up sharply, affect its working efficiency badly and even cause safety problem [1, 2]. Sato[3] analyzed the thermal behavior of lithium-ion batteries showing that when the battery temperature was over $50{ }^{\circ} \mathrm{C}$, charging efficiency and life cycle would be considerably diminished. Khateeb et al. [4] pointed out that the safety of the Li-ion battery would descend when it operated at the temperature range of $70-100{ }^{\circ} \mathrm{C}$. Studies have shown that there is a necessary temperature range for battery to make sure its performance and service life. Pesaran [5] presented that the best range of operating temperature for batteries such as lead-acid, $\mathrm{NiMH}$, and Li-ion are from 25 to $40^{\circ} \mathrm{C}$ and suitable temperature distribution from module to module is below $50^{\circ} \mathrm{C}$. To control the batteries in the suitable temperature 
range, there are several methods presented [6-12], such as by air directly, by liquid with plate heat exchanger or by refrigerant phase change with plate or pipe heat

71 exchanger. However, investigations on the thermal behavior of batteries [5,13-14]

72 show that the relationship between the generated heat and discharge rate is nonlinear

73 direct ratio and the higher the discharge rate is, the quicker the increase rate of the

74 generated heat will be. While the discharge rate changes with the working conditions

75 such as acceleration, deceleration, uphill, and downhill. So generated heat of the

76 battery is variable and its instantaneous value is very high. This means the cooling

77 capacity of the battery temperature control system with these normal methods has to

78 be set high enough to avoid the battery on extremely high temperature and lead to an

79 over-size thermal management system. Therefore it is very significant to search for a

80 more efficient battery heat-transfer method to simplify the EV thermal management

81 system.

Heat pipe, as a high efficient heat-transfer device combining the principles of

83 both thermal conductivity and phase transition, is a novel idea to apply on the

84 temperature control of EV battery [15]. Actually, because of its highly effective

85 thermal conductivity, heat pipe has been applied successfully in many fields such as

86 electron cooling, solar heater and energy recovering [16, 17]. As for the above

87 mentioned EV battery thermal characteristics, heat pipes between the batteries can

88 help transfer the heat out to the coolant so that the batteries can be maintained in the

89 best operating temperature range under variable working conditions and the 
91 the coolant system has enough thermal capacity, the cooling load can be much lower

92 than that of the instant cooling method. It just needs to meet the average heat

93 dissipation demand instead of the peak generated heat during high discharge rate

94 conditions. Therefore, heat pipe is a promising development orientation for batteries

95 thermal management of EV. Authors' initial investigations have shown that the heat

96 pipe cooling is an effective method [19]. However, the previous study results were

97 mainly concentrating on the basic thermal performance of a single heat pipe unit with

98 a simple experimental apparatus. The thermal performance of the heat pipe heat

99 exchanger (HPHE) for the practical EV battery group still has not been researched,

100 which might be different from that of the single heat pipe because of cluster effect.

101 On the other hand, since EV has no engine to drive compressor for cooling and

102 no waste engine heat for heating, heat pump system with motor-driven compressor is

103 an important development trend. The investigation on the performance of heat pump

104 system has become a major topic of EV air-conditioning. Suzuki and Katsuya [20]

105 proposed a heat pump system for electric vehicle with functions of cooling, heating,

106 demisting and dehumidifying and their experimental results showed the feasibility of

107 heat pump. However, heat pump system has a shortcoming that its heating capacity

108 drops sharply with the decreasing outdoor temperature. Hosoz and Direk [21, 22]

109 indicated this feature by investigating the performance of R134a heat pump system

110 transformed for the original automobile air conditioning system. In recent years many 
111 advances on heat pump system for EV have been presented [23]. Authors [24, 25]

112 have also engaged in the heat pump performance improvement with injection

113 technology and got notable achievement in system heating capacity and COP under

114 extremely cold condition. However when it comes to practical performance of the

115 heat pump system combining with battery temperature control system, there is few

116 literature either.

117 In this paper, an integrated thermal management system combining a HPHE for 118 battery cooling/preheating with a heat pump air conditioning is presented to

119 investigate its performance characteristics on different working conditions. Cooling

120 and heating performances of the system, as well as the thermal performance of HPHE,

121 are investigated by bench test, hoping to present a significative reference for the EV

122 thermal management.

123 2. System description and experimental bench setup

$124 \quad 2.1$ System description

125 Fig.1 shows the diagram of the heat pump coupling with battery cooling

126 /preheating system based on regular five-chair electric cars and takes R134a as

127 refrigerant. Its working temperature ranges from $-20^{\circ} \mathrm{C}$ to $45^{\circ} \mathrm{C}$. The heat pump system

128 mainly consists of a variable-frequency scroll compressor, an outside heat exchanger

129 with a fan, a liquid vapour separator, four refrigerant valves (RV), a condenser

130 followed by an expansion valve (EXV1) for cabinet heating, an refrigerant-air 
131 evaporator following with EXV2 for cabinet cooling and a refrigerant-water

132 evaporator for battery cooling called battery chiller. The refrigerant-air evaporator and

133 condenser are installed in the ventilation duct. The system is switched by the RVs for

134 cooling or heating. The battery cooling/preheating system also applies a water-air heat

135 exchanger in front of the car to utilize the natural cooling source and a Positive

136 Temperature Coefficient (PTC) heater to preheat the battery in cold season. A HPHE

137 is installed among the battery group, called battery heat exchanger box here. Please

138 refer the reference [20] for more details of the HPHE.

139

140

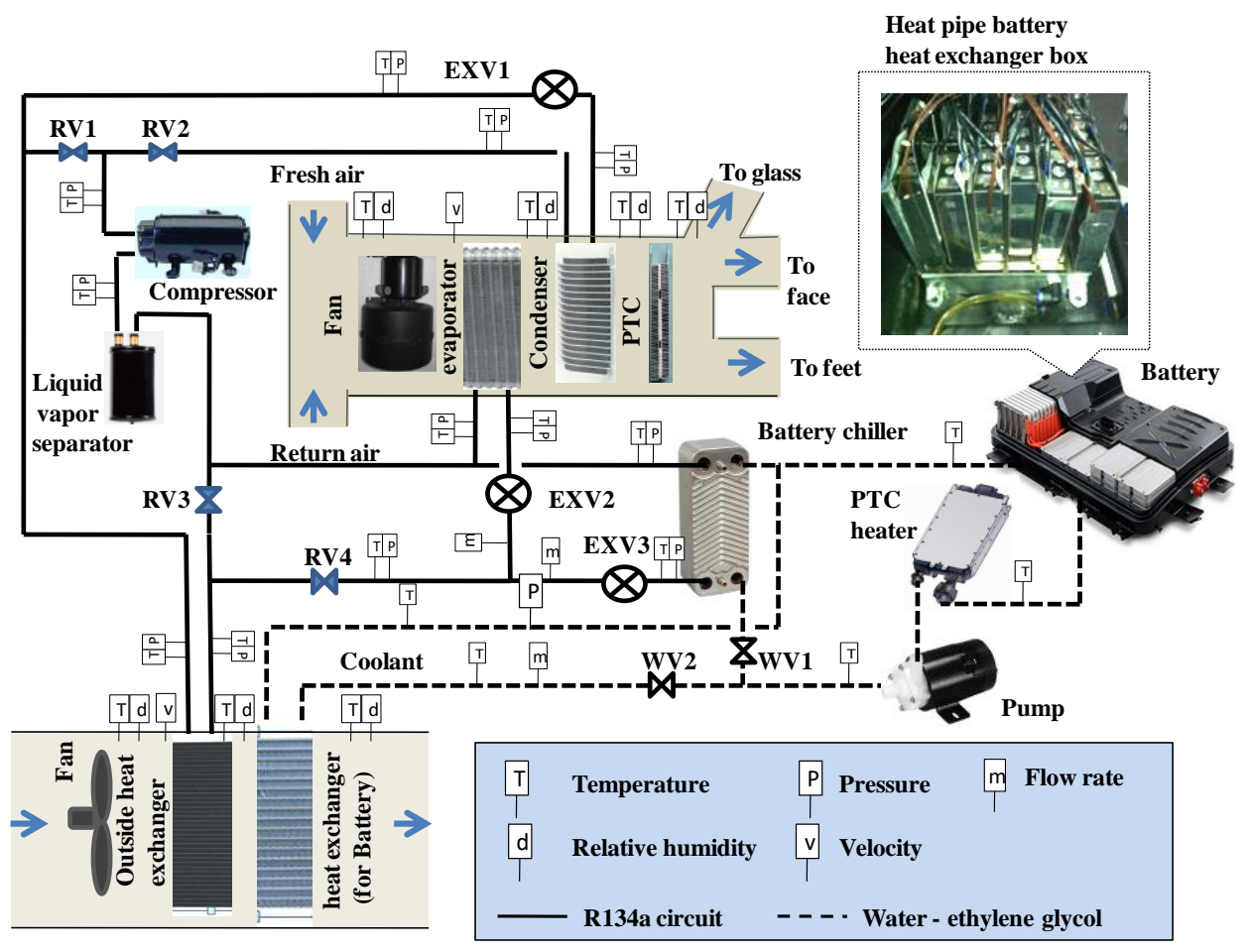

Fig.1.Diagram of the heat pump coupling with the battery cooling/preheating system

$141 \quad 2.2$ Experimental bench

142 Correspondingly a test bench is set up inside of a psychrometer testing room to

143 investigate the performance of this system. The experiments are carried out on 
144 cooling and heating mode respectively under different working conditions. On

145 cooling mode, the refrigerant valve RV1 and RV4 are open while RV2 and RV3 are

146 closed. The opening of expansion valves EXV2 and EXV3 are changed repeatedly to

147 get the optimum branch refrigerant flow rate of the cabin evaporator and battery

148 chiller. On heating mode, the refrigerant valve RV1 and RV4 are closed while RV2

149 and RV3 are open. The battery is preheated by the PTC heater. The coolant pipe

150 system and battery heat exchanger box are isolated to prevent unmeasured heat loss.

151 There are 30 real battery modules in the bench for electric cars, but the generated heat

152 during discharging process is simulated by electric films for the sake of safety. The

153 electric films are pasted on the two wide sides of each battery module and

154 thermocouples are pasted on the other two narrow sides to measure the temperature

155 response of the batteries. Each side has three thermocouples. The measurement

156 devices of the bench are shown in Fig.1 and their parameters are shown in Table 1.

157 The relative parameters of the bench are shown in Table 2.

158

Table 1 Measurement devices

\begin{tabular}{llll}
\hline Parameter & Type & Range & Error \\
\hline Temperature & Thermocouple & -30 to $220^{\circ} \mathrm{C}$ & $\pm 0.5^{\circ} \mathrm{C}$ \\
Pressure & Diaphragm & 0 to $30 \mathrm{bar}$ & $\pm 0.5 \%$ \\
Air speed & Hot bulb & 0 to $40 \mathrm{~m} / \mathrm{s}$ & $\pm 3 \%$ \\
Mass flow rate of Ref. & Coriolis & $<370 \mathrm{~kg} / \mathrm{h}$ & $\pm 0.1 \%$ \\
\hline
\end{tabular}

159

160

Table 2 Parameter of the bench

\begin{tabular}{lll}
\hline Item & Symbol & Value(unit) \\
\hline
\end{tabular}




\begin{tabular}{ccc}
\hline Mass of battery group & $m_{\mathrm{b}}$ & $16.03 \mathrm{~kg}$ \\
Mass of coolant & $m_{\mathrm{c}}$ & $3.96 \mathrm{~kg}$ \\
Specific heat of ethylene glycol coolant & $c_{\mathrm{c}}$ & $3.518 \mathrm{~kJ} / \mathrm{kg}^{\circ} \mathrm{C} @ 35^{\circ} \mathrm{C}$ \\
hontact superficial area with coolant of each & & $3.552 \mathrm{~kJ} / \mathrm{kg}^{\circ} \mathrm{C} @ 45^{\circ} \mathrm{C}$ \\
heat pipe & $A_{\mathrm{hp}}$ & $0.00188 \mathrm{~m}^{\circ} \mathrm{C}$ \\
Heat pipe number & & 25 \\
\hline
\end{tabular}

161

$162 \quad 2.3$ Calculation methodology

163 To investigate the heat transfer performance of HPHE of battery group, the

164 experiment is carried out to simulate different working modes. The heat composition

165 of the battery temperature control system is shown as Fig.2. The battery internal heat

166 variation and coolant internal heat variation can be expressed as equation (1) and (2)

167 respectively. Here heat transfer coefficient of each heat pipe $q_{\mathrm{hp}}$ is applied to indicate

168 the heat transfer performance of the HPHE, which can be expressed as equation(3).

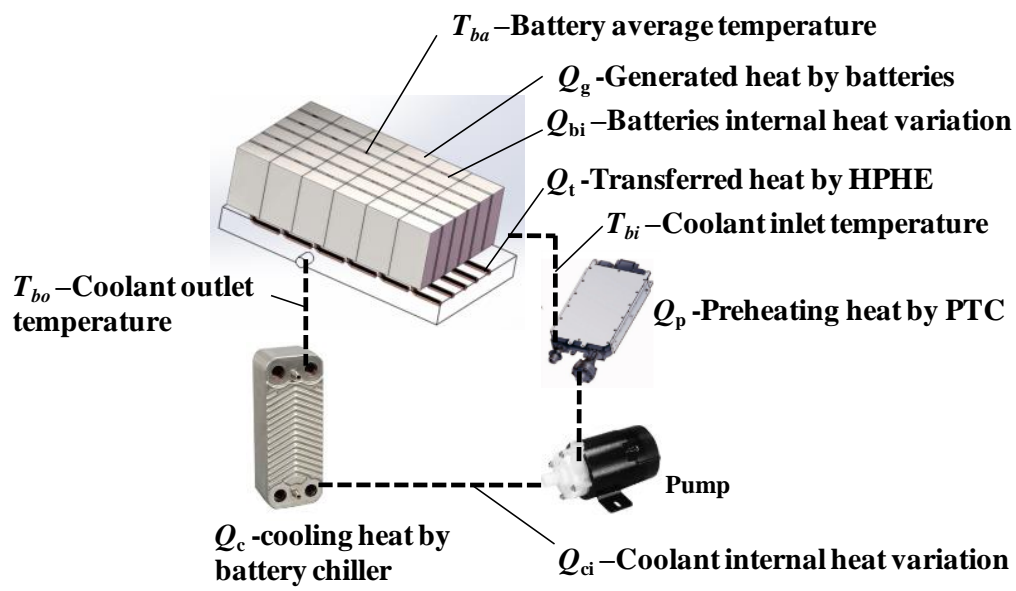

$$
Q_{b i}=c_{b} m_{b} \frac{d T_{b a}}{d t}=Q_{g}+Q_{t}
$$


$173 \quad q_{h p}=\frac{Q_{t}}{n \Delta T}$

174 Because the system heat-transfer process goes from dynamic to steady state

175 gradually and the energy during the initial dynamic process is not balanced, it is

176 important to note that this model is only suitable for the final steady state.

\section{Experimental result and discussion}

178

179

180

181

Table 3 Cooling/heating performance of the heat pump system

\begin{tabular}{|c|c|c|c|c|c|c|}
\hline Experiment No. & 1 & 2 & 3 & 4 & 5 & 6 \\
\hline Out-car temperature $\left({ }^{\circ} \mathrm{C}\right)$ & 35 & 35 & 45 & 45 & -20 & -20 \\
\hline In-car temperature $\left({ }^{\circ} \mathrm{C}\right)$ & 27 & 27 & 45 & 45 & -20 & 20 \\
\hline EXV1 opening (\%) & 0 & 0 & 0 & 0 & 100 & 100 \\
\hline EXV2 opening (\%) & 84 & 84 & 63 & 63 & 0 & 0 \\
\hline EXV3 opening (\%) & 0 & 40 & 0 & 90 & 0 & 0 \\
\hline Evaporator evaporating temperature $\left({ }^{\circ} \mathrm{C}\right)$ & -1.49 & -0.48 & 9.96 & 11.7 & -23.13 & -21.58 \\
\hline Super-heating temperature $\left({ }^{\circ} \mathrm{C}\right)$ & 0.93 & 0.76 & 1.28 & 2.59 & 0.01 & 1.37 \\
\hline Battery chiller evaporating temperature $\left({ }^{\circ} \mathrm{C}\right)$ & -- & -4.30 & -- & 7.49 & -- & -- \\
\hline Super-heating temperature $\left({ }^{\circ} \mathrm{C}\right)$ & -- & 18.35 & -- & 0.36 & -- & -- \\
\hline Condensing temperature $\left({ }^{\circ} \mathrm{C}\right)$ & 41.18 & 41.58 & 55.4 & 54.31 & 20.78 & 58 \\
\hline Sub-cooling temperature $\left({ }^{\circ} \mathrm{C}\right)$ & 0.3 & 0 & 7.36 & 1.98 & 21.62 & 9.45 \\
\hline Cabinet refrigerant flow rate $(\mathrm{kg} / \mathrm{h})$ & 135.16 & 134.0 & 192.01 & 180.4 & 43.2 & 47.56 \\
\hline Cabinet cooling/heating capacity $(\mathrm{kW})$ & 5.24 & 5.19 & 7.22 & 6.61 & 2.96 & 2.75 \\
\hline Battery chiller refrigerant flow rate $(\mathrm{kg} / \mathrm{h})$ & -- & 25.36 & -- & 63.96 & -- & -- \\
\hline
\end{tabular}




\begin{tabular}{lcccccc}
\hline Battery chiller cooling capacity $(\mathrm{kW})$ & -- & 1.09 & -- & 2.31 & -- & -- \\
\hline Theoretical compression power $(\mathrm{kW})$ & 1.04 & 1.24 & 1.43 & 1.75 & 0.45 & 0.86 \\
\hline Actual input power $(\mathrm{kW})$ & 2.44 & 2.46 & 3.13 & 3.19 & 1.48 & 2.04 \\
\hline Compression efficiency $(\%)$ & 42.51 & 50.34 & 45.53 & 55.0 & 30.27 & 42.05 \\
\hline COP & 2.15 & 2.55 & 2.31 & 2.80 & 2.0 & 1.34 \\
\hline
\end{tabular}

182

183 On cooling mode under out-car $35^{\circ} \mathrm{C}$ and in-car $27^{\circ} \mathrm{C}$ condition, the opening of

184 EXV1 is kept on $84 \%$ while that of EXV3 is changed from 0 to $40 \%$. The evaporator

185 cooling capacity deceases lightly and the battery chiller cooling capacity increases

186 quickly. The total cooling capacity increases about $19.84 \%$ and the compressor input

187 power almost keeps the same, so the system COP increases about $18.60 \%$. Under

188 out-car $45^{\circ} \mathrm{C}$ and in-car $45^{\circ} \mathrm{C}$ condition, the optimum opening of EXV2 is $63 \%$ and

189 that of EXV3 is $90 \%$. And also the system total cooling capacity and COP under this

190 conditions are both increases. Compare to the out-car $35^{\circ} \mathrm{C}$ and in-car $27{ }^{\circ} \mathrm{C}$

191 condition, the cooling capacity for both cabin and battery as well as system COP are

192 much higher because of the lower compression ratio under this condition. The

193 experimental results of cooling performance show that the additional parallel branch

194 of battery chiller is a good way to solve the battery cooling problem, which can

195 supply about $20 \%$ additional cooling capacity without input power increase.

196 On heating mode under out-car $-20^{\circ} \mathrm{C}$ and in-car $-20^{\circ} \mathrm{C}$ condition, system

197 condensing temperature is about $20^{\circ} \mathrm{C}$. As the in-car temperature increases to $20^{\circ} \mathrm{C}$,

198 system condensing temperature increases to $58^{\circ} \mathrm{C}$, heating capacity decreases from 
199

$2.96 \mathrm{~kW}$ to $2.75 \mathrm{~kW}$, the compressor input power increases from $1.48 \mathrm{~kW}$ to $2.04 \mathrm{~kW}$, and the heating COP decreases from 2.0 to 1.34. The experimental results show that although the heating $\mathrm{COP}$ under $-20^{\circ} \mathrm{C}$ in-car temperature is higher than that under $20^{\circ} \mathrm{C}$ because of the lower compression ratio, the compression efficiency of the scroll compressor is much lower. This is because the motor efficiency of scroll compressor drops rapidly under lower load conditions. The heating capacity is insufficient for the cabinet heating. Therefore PTC heater is suggested to be an auxiliary heat source under extremely cold weather.

\subsection{Heat pipe heat exchanger performance}

\subsubsection{Testing mode without heating or cooling}

Because the battery group is a composition of electrolyte, metal and heat pipe etc., and the thermal capacity characteristics of different material are different, the specific heat of battery group is uncertain. A testing experiment is carried out firstly to test the specific heat of battery group. On this mode, the coolant is circulated by the pump with neither PTC heating nor battery chiller cooling and the generated heat of battery group is dissipated to the coolant by the HPHE. The equation (1) and (2) can be transferred into equation (4).

$$
c_{b} m_{b} \frac{d T_{b a}}{d t}=Q_{g}-c_{c} m_{c} \frac{d T_{c a}}{d t}
$$

Fig.3(a) shows the average temperature response tendency of the battery group and the coolant from start to steady state. The temperature difference between them decreases from $11.6^{\circ} \mathrm{C}$ to a constant $4.4^{\circ} \mathrm{C}$. Fig.3(b) shows the internal heat variation 
221 response tendency of the battery group and the coolant. As mentioned in the above 222 calculation methodology, the model applied for the steady state is quasi-steady and it 223 is not suitable for the dynamic process. So the initial calculated heat shown in Fig.3(b), 224 which goes up to more than $200 \mathrm{~W}$, does not present the actual heat value. The average 225 internal heat variation of the battery group and the coolant at the steady state is around $226119.4 \mathrm{~W}$ and 83.6W respectively. Therefore according to equation (4), the specific heat 227 of battery group can be gained, which about $1.24 \mathrm{~kJ} / \mathrm{kg}^{\circ} \mathrm{C}$. This result has also been 228 verified by the following experiment based on the equation (1) and (2).

229

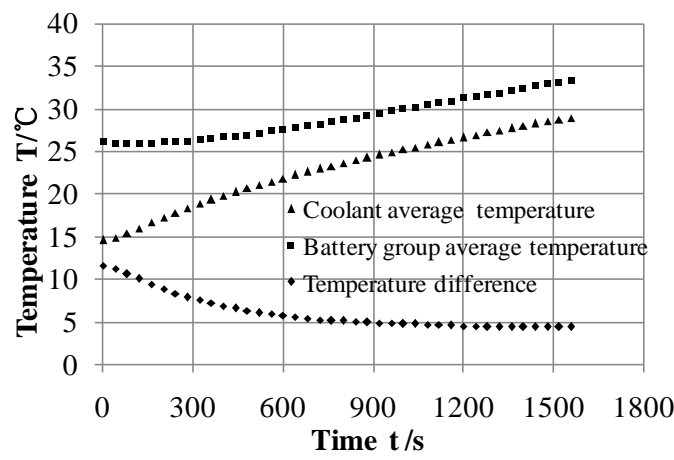

(a) Temperature response tendency

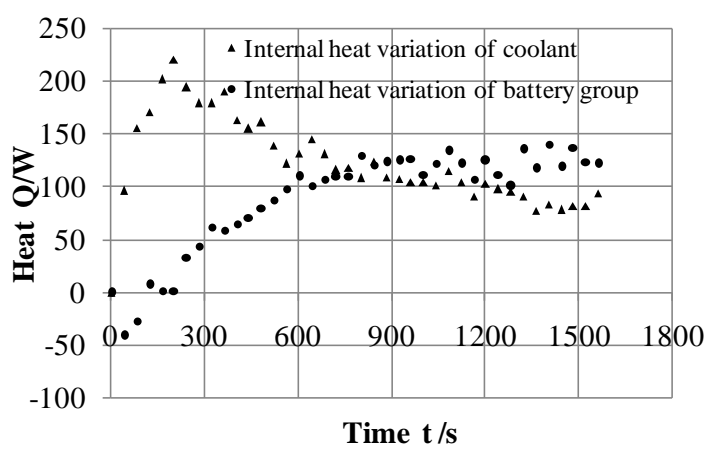

(b) Internal heat variation response tendency

Fig.3 Experimental response tendency

Heat transfer way of the heat pipe under this condition is shown as Fig 4.The top part $a$ of the heat pipe absorbs heat from battery and the fluid inside takes the heat to the bottom part $b$ to dissipate to the coolant. The fluid inside of the heat pipe evaporates at the top part, goes down to the bottom part by pressure, and goes up by capillary action after condensation. The heat transfer performance of each heat pipe (Fig.5) can be obtained by equation (3) and it shows that as the experiment goes to steady state the heat transfer performance of each heat pipe gets to a relative stable value, which is around $0.86 \mathrm{~W} /{ }^{\circ} \mathrm{C}$. 


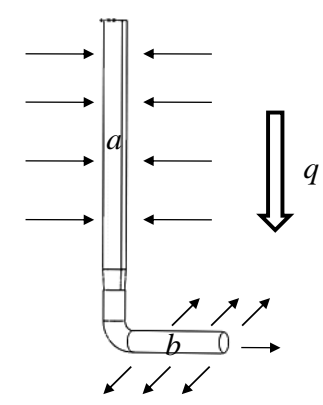

Fig.4 Heat transfer way of the heat pipe

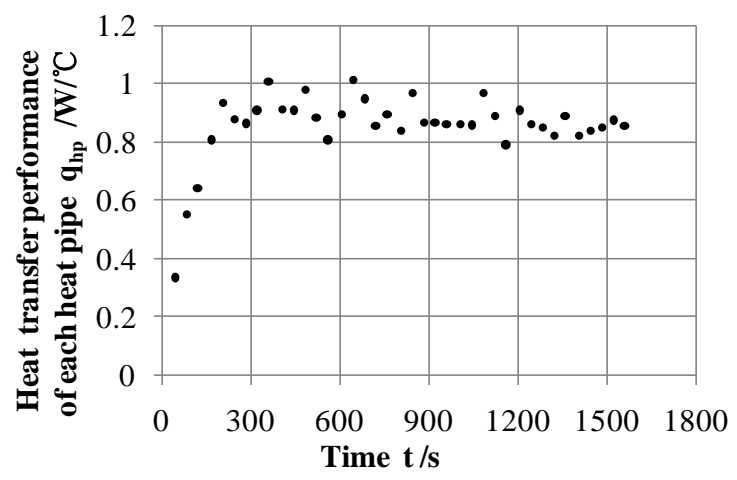

Fig.5 Heat transfer performance of each heat pipe

\subsubsection{Cooling mode}

On this mode the coolant is circulated by the pump with battery chiller cooling

244 and the battery group generates heat. The cooling capacity of the battery chiller is

245 adjusted by changing the opening degree of EXV3.

Fig. 6 shows the temperature response of the battery cooling process. At the beginning, the battery group and the coolant are on the same temperature condition. As the cooling mode starts, the coolant average temperature inside of the battery exchanger box decreases quickly. While the battery average temperature increases to a higher value firstly and then begins to decrease with the coolant. It is worthy of mention that as the battery average temperature increases to the highest point, the temperature differences between the coolant and the battery group are all in the range of $7 \sim 8^{\circ} \mathrm{C}$ under every experimental condition. This result shows that at the beginning

254 of this experimental mode, the battery begins to generate heat as it supplies power 255 while the HPHE does not start until the temperature difference goes up to $7 \sim 8^{\circ} \mathrm{C}$. 256 Therefore the battery group temperature will go up before the HPHE starts to transfer 257 heat from the battery to the coolant. And finally the battery temperature decreases to 
258 its suitable range. The battery cooling rate depends on the EXV3 opening degree.

259 Under the conditions of 33\% EXV3 opening degree, it takes about 1040s to be cooled 260 from $35^{\circ} \mathrm{C}$ to $30^{\circ} \mathrm{C}, 1720 \mathrm{~s}$ from $45^{\circ} \mathrm{C}$ to $30^{\circ} \mathrm{C}$. Under the conditions of $60 \% \mathrm{EXV} 3$

261 opening, it takes 600 s from $35^{\circ} \mathrm{C}$ to $30^{\circ} \mathrm{C}, 1180$ s from $45^{\circ} \mathrm{C}$ to $30^{\circ} \mathrm{C}$.

262

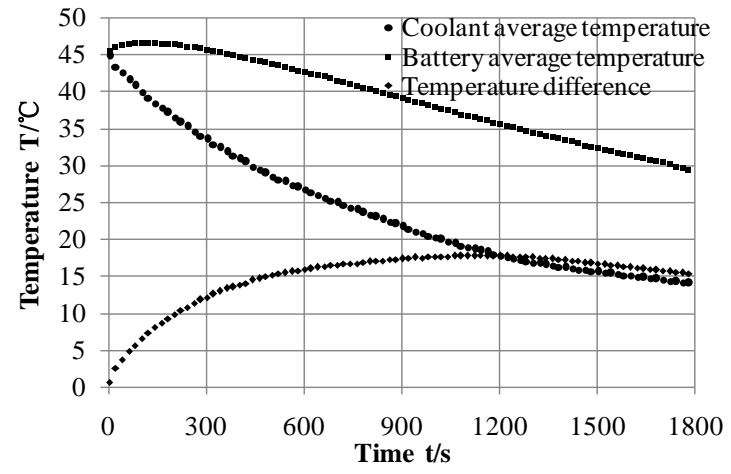

(b) $45^{\circ} \mathrm{C} / 33 \%$

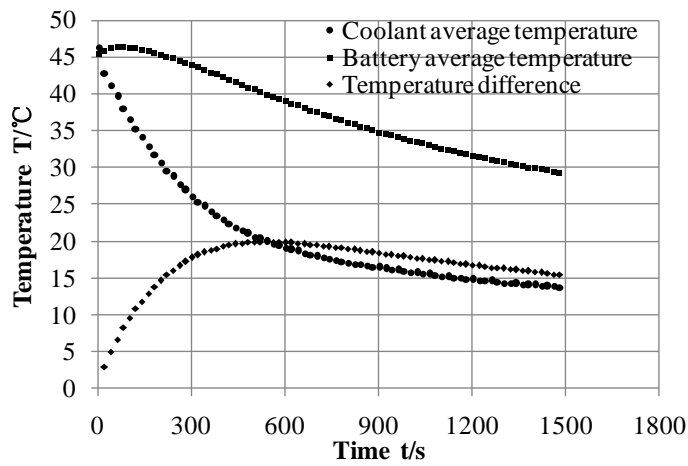

(d) $45^{\circ} \mathrm{C} / 60 \%$

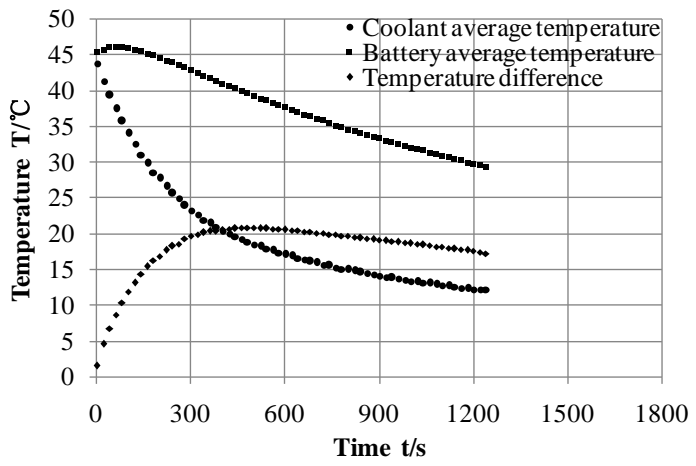

(f) $45^{\circ} \mathrm{C} / 100 \%$ 
270 equations (1) (3). Heat transfer way of the heat pipe under this condition is the same

271 as fig 3.The results show that as the system runs to steady state the values of the heat

272 pipe heat transfer performance on different working conditions go to be coincident,

273 which is around $0.87 \mathrm{~W} /{ }^{\circ} \mathrm{C}$. This result is also fitting very well with the above 274 experimental result. According to this result, the total heat transfer performance of the 275 HPHE is easily to be estimated, so that the temperature difference between coolant 276 and battery group can be determined accordingly in the real application.
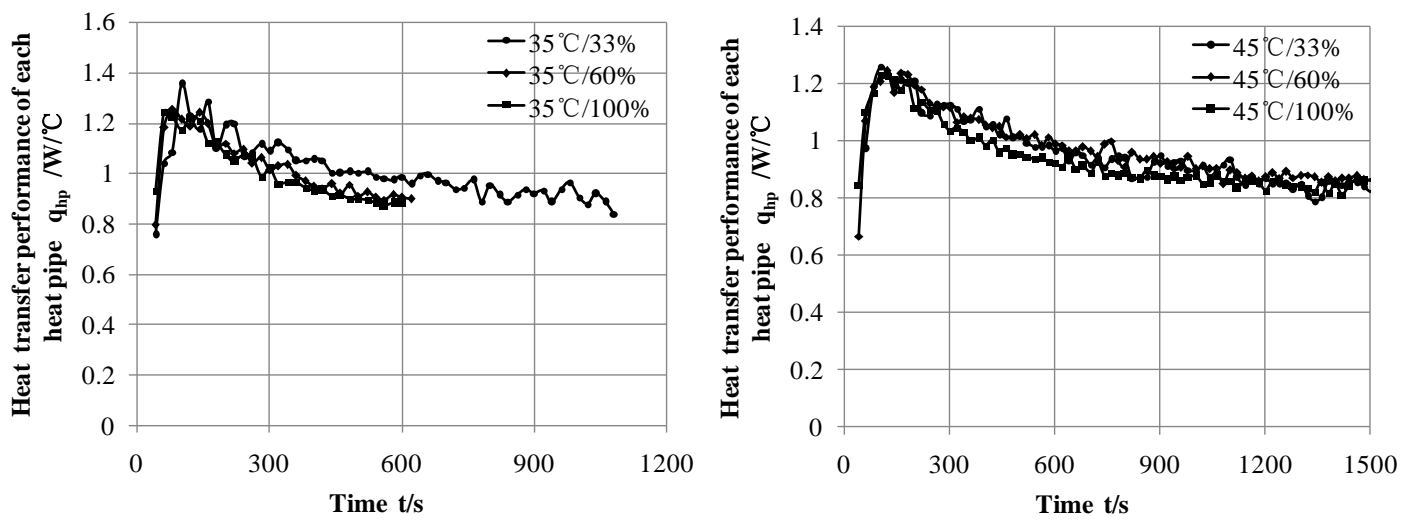

Fig.7 Heat transfer performance of each heat pipe on cooling mode

$279 \quad$ 3.2.3 Preheating mode

280 On this mode the coolant is circulated by the pump with PTC heating and the

281 battery group begins to generate heat when its temperature gets to be higher than $0^{\circ} \mathrm{C}$.

282 Fig. 8 shows the temperature response of the battery preheating process under $-20^{\circ} \mathrm{C}$

283 out-car temperature. The coolant average temperature increases quickly as the PTC

284 heater is on. But the battery response temperature does not change at the first stage of

285200 s until the coolant temperature goes up to be $2^{\circ} \mathrm{C}$. After then it begins to increase 
gradually with the increasing of the coolant temperature. This means the heat pipe also has a start condition on heating mode. The start temperature of its bottom evaporating terminal is about $2^{\circ} \mathrm{C}$ and the temperature difference between the rate of the battery temperature is getting higher after $0^{\circ} \mathrm{C}$.
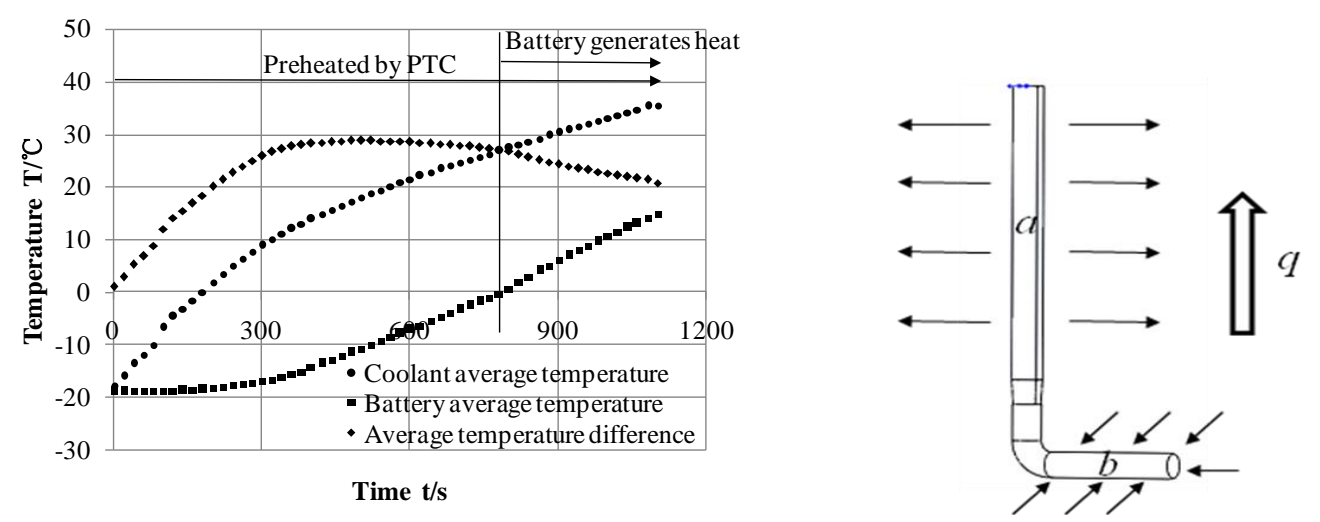

Fig.8 Temperature response on preheating mode

Fig.9 Heat transfer way of the heat pipe
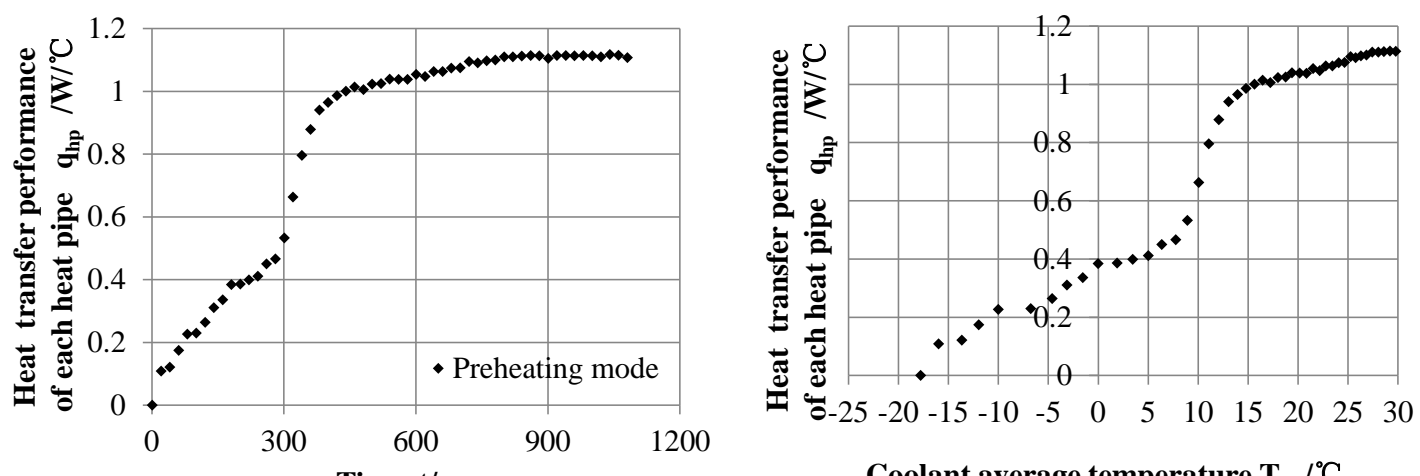

Time $\mathbf{t} / \mathbf{s}$

Coolant average temperature $\mathrm{T}_{\mathrm{ca}} /{ }^{\circ} \mathrm{C}$

Fig.10 Heat transfer performance on preheating mode

Fig 9 shows the heat transfer way of the heat pipe under preheating mode. The 
wall of the pipe after condensation. Fig.10 shows the heat transfer performance of

301 each heat pipe on preheating mode. At first the heat transfer performance increases

302 gradually at a relative low level with the increasing of the temperature difference. As

303 the coolant temperature goes up to be higher than $8^{\circ} \mathrm{C}$, the heat transfer performance

304 jumps up quickly to a higher value, and then increases slowly to a relative stable value,

305 which is about $1.11 \mathrm{~W} /{ }^{\circ} \mathrm{C}$. This result verifies that the coolant temperature has

306 important effect on the heat transfer performance of the HPHE because the

307 evaporating and condensing process of the fluid inside of the heat pipe depends on the

308 temperatures of its two terminals. Meanwhile, compare to the heat transfer

309 performance of the heat pipe on cooling mode, that on heating mode is higher. This is

310 because on heating mode the heat pipes can take advantage of the gravity role to get

311 better heat transfer performance. The HPHE designed for this experimental bench can

312 be on a good heat transfer performance when the coolant average temperature is

313 higher than $15^{\circ} \mathrm{C}$.

\section{4. Conclusion}

315 According to the above experimental research on an integrated thermal

316 management system for EV, the cooling and heating performance of heat pump

317 system and heat transfer performance of HPHE are investigated. The research results

318 show that the presented system works well as an effective thermal management

319 method for EV. The main conclusions go as following: 
320 (1) The system cooling performance shows that the additional parallel branch of

321 battery chiller is a good way to solve the battery group cooling problem, which can

322 supply about $20 \%$ additional cooling capacity without input power increase. The

323 cooling capacity distribution of each branch under different working conditions can

324 be optimized by adjusting the expansion valve.

325 (2) The system heating performance under extremely cold condition shows that

326 although the heating COP under $-20^{\circ} \mathrm{C}$ in-car temperature is higher than that under

$32720^{\circ} \mathrm{C}$, the compression efficiency of the scroll compressor is much lower because the

328 motor efficiency of scroll compressor drops rapidly under lower load conditions. So

329 improving the heating performance under high temperature difference condition is

330 still an important future work for EV.

331 (3) The specific heat of the battery group is tested about $1.24 \mathrm{~kJ} / \mathrm{kg}^{\circ} \mathrm{C}$. On cooling

332 mode, there is a delay for the HPHE to start heat transfer and the temperature

333 difference for the HPHE to start between its two terminals is about $7 \sim 8^{\circ} \mathrm{C}$. The heat

334 pipe heat transfer performance on different cooling working conditions is around 0.87

$335 \mathrm{~W} /{ }^{\circ} \mathrm{C}$.

336 (4) On preheating mode, the HPHE also has a necessary start condition. The start

337 temperature of the bottom evaporating terminal is about $2{ }^{\circ} \mathrm{C}$ and the temperature

338 difference between the two terminals is about $22^{\circ} \mathrm{C}$. The coolant temperature has

339 important effect on the heat transfer performance of HPHE. As the coolant

340 temperature goes up to be higher than $8^{\circ} \mathrm{C}$, the heat transfer performance jumps up 
341 quickly to a higher value, and then increases slowly to a relative stable value, which is

342 about $1.11 \mathrm{~W} /{ }^{\circ} \mathrm{C}$. The heat transfer performance of the heat pipe on preheating mode,

343 is higher than that on heating mode because it can take advantage of the gravity role.

344 (5) The research results show that the heat transfer performance of HPHE can meet

345 the demand of battery temperature control on different working conditions. According

346 to the heat transfer performance of the HPHE and specific heat of the battery group,

347 the design parameters of the coolant system can be determined based on the 348 calculation methodology in the real applications.

\section{5. Acknowledgements}

We would like to thank the support by the Natural Science Foundation of China

351 (No. 51576203) and the External Cooperation Program of BIC, Chinese Academy of 352 Sciences (No. 1A1111KYSB20130032)

353 6. References

354 [1] Chen Y, Evans JW. Heat transfer phenomena in lithium/ polymer- electrolyte

355 batteries for electric vehicle application. Journal of the Electrochemical Society. 1993; $356 \quad 140: 6$.

357 [2] Song L, Evans JW. The thermal stability of lithium polymer batteries. Journal of 358 Electrochemical Society.1998; 145: 2327-2334.

359 [3] Sato N. Thermal behavior analysis of lithium-ion batteries for electric and hybrid 360 vehicles. Journal of Power Sources, 2001; 99:70-77. 
361 [4] Khateeb SA, Amiruddin S, et al. Thermal management of Li-ion battery with 362 phase change material for electric scooter: experiment validation. Journal of Power 363 Sources, 2005; 142:345-353.

364 [5] Pesaran AA. Battery thermal models for hybrid vehicle simulations. Journal of 365 Power Sources. 2002; 110: 377-382.

366 [6] BEHR. Thermal Management for Hybrid Vehicles. Technical Press Day. 2009.

367 [7] Mahamud R, Park C. Reciprocating air flow for Li-ion battery thermal 368 management to improve temperature uniformity. Journal of Power Sources. 2011; 369 196(13):5685-96.

370 [8] Wu MS, Liu KH, Wang YY, Wan CC. Heat dissipation design for lithium-ion 371 batteries. Journal of Power Sources 2002;109(1):160

372 [9] Al Hallaj S, Selman JR. A novel thermal management system for electric vehicle 373 batteries using phase-change material. Journal of Electrochemical Society. 2000; 374 147(9):3231.

375 [10] Ling Z, Chen J, et al. Experimental and numerical investigation of the application 376 of phase change materials in a simulative power batteries thermal management system. 377 Applied Energy. 2014;121:104-113.

378 [11] Wang T, Tseng KJ, et al. Thermal investigation of lithium-ion battery module 379 with different cell arrangement structures and forced air-cooling strategies. Applied 380 Energy. 2014;134:229-238.

381 [12] Zhao JT, Rao ZH, Li YM. Thermal performance of mini-channel liquid cooled 
cylinder based battery thermal management for cylindrical lithium-ion power battery.

[13] Khateeb SA. Amiruddin S. et al. Thermal management of Li-ion battery with phase change material for electric scooter: experiment validation. Journal of Power Sources, 2005;142:345-353.

[14] Kim US, Shin CB, Kim CS. Modeling for the scale-up of a lithium-ion polymer battery. Journal of Power Sources. 2009; 189:841-846. performance heat pipes. Applied Thermal Engineering. 2012; 33-34:1-14.

[16] Esen M, Esen H. Experimental investigation of a two-phase closed 392 thermosyphon solar water heater. Solar Energy. 2005; 79(5):459-468.

393 [17] Remeli MF, Date A, Ding LC, et al. Experimental investigation of combined heat 394 recovery and power generation using a heat pipe assisted thermoelectric generator system. Energy Conversion and Management. 2016; 111: 147-157.

[18] Rao Z, W SH. Experimental investigation on thermal management of electric vehicle batterywith heat pipe. Energy Conversion and Management. 2013; 65:92-97. $401 \quad$ paper no. 960688.

402 [21] Hosoz M, Direk M. Performance evaluation of an integrated automotive air 403 conditioning and heat pump system. Energy Conversion and Management. 2006; 47: 
405 [22] Direk M, Hosoz M, et al. Experimental performance of an R134a automobile 406 heat pump system coupled to the passenger compartment. World renewable energy 407 congress 2011. Sweden.

408 [23] Qi ZG. Advances on air conditioning and heat pump system in electric vehicles 409 A review. Renewable and Sustainable Energy Reviews. 2014;38: 754-764.

410 [24] Qin F, Zou HM, Tian CQ, et al. Experimental investigation on heating 411 performance of heat pump for electric vehicles at $-20{ }^{\circ} \mathrm{C}$ ambient temperature. Energy 412 Conversion and Management.2015;102: 39-49.

413 [25] Qin F, Zou HM, Tian CQ, et al. Experimental investigation and theoretical 414 analysis of heat pump systems with two different injection portholes compressors for 415 electric vehicles. Applied Energy. 2016, In Press. 